\title{
Estratégias de design para o desenvolvimento de produtos de moda na perspectiva da sustentabilidade
}

\section{Design strategies for the development of fashion products in the perspective of sustainability}

\author{
Andréia Mesacasa \\ Doutora em Design pela Universidade Federal do Paraná (UFPR) - andreiamesacasa@hotmail.com - \\ http://orcid.org/0000-0002-1280-0756 \\ Patrícia Sorgatto \\ Especialista em Psicopedagogia pela Instituto Federal de Educação, Ciência e Tecnologia do Rio Grande do Sul (IFRS) \\ psorgatto@hotmail.com - https://orcid.org/0000-0001-8263-4653
}

\section{Resumo}

Diante de um cenário de insustentabilidade ambiental onde a indústria da moda encontra-se inserida, devido a produção e consumo excessivo de recursos naturais aliado ao modelo de desenvolvimento econômico, o presente artigo objetiva investigar e sintetizar estratégias presentes na literatura relacionada ao design para a sustentabilidade para promover o enfrentamento deste cenário, bem como direcionar a prática do profissional designer de moda. A metodologia utilizada neste estudo foi orientada pelo método de revisão bibliográfica integrativa associado à representação gráfica de síntese, onde foi construída uma mandala com a intenção de representar a síntese das estratégias propostas. $O$ estudo mostrou como, de fato, o designer de moda exerce grande influência na mudança para o novo paradigma sustentável, ao compreender com profundidade todo o sistema de moda, bem como ao reconhecer a complexidade e dificuldades que demandam novas estratégias para o desenvolvimento de produtos com vistas a novos estilos de vida que respeitem o ciclo de vida, previstos nas dimensões que regem o desenvolvimento sustentável.

Palavras-chave: Moda. Ambientalismo. Desenvolvimento sustentável. Designers de moda.

\begin{abstract}
Taking into consideration a scenario of environmental unsustainability where the fashion industry is placed, due to production and overuse of natural resources, together with the current economic development model, this work aims to investigate and synthesize strategies present in the literature related to design for sustainability to promote the confrontation of this scenario, as well as direct the practice of the fashion designer. The methodology employed in this study was guided by the integrative bibliographic review method associated to the graphical representation of synthesis, where a circular mandala was assembled with the intention of representing the synthesis of the proposed strategies. The study showed how, in fact, fashion designer has a great influence in the change to the new sustainable paradigm, to understand in depth the whole system of fashion, as well as to recognize the complexity and difficulties that demand new strategies for the development of products with a view to new lifestyles that respect the life cycle, expected in the dimensions that rule sustainable development.
\end{abstract}

Keywords: Fashion. Environmentalism. Sustainable development. Fashion designers.

Recebido em: 02/06/2020

Aceito em: 03/10/2020 


\section{INTRODUÇÃO}

A busca incessante pelo crescimento econômico ilimitado denota a insuficiência desse sistema, uma vez que são inúmeras as consequências das diversas atividades destinadas à criação do mundo artificial, criação esta que permite ao ser humano sobreviver no mundo natural.

O design é uma das áreas do conhecimento responsável por criar o mundo artificial. Para tanto, necessita de uma visão sistêmica dos problemas humanos, a fim de elencar possíveis soluções para estes. Neste campo de ação, para que ocorra o enfretamento de problemas causados pelas diversas atividades relativas à produção, ao consumo e ao descarte de bens e serviços é necessária uma convergência entre a sustentabilidade e o design (VEZZOLI, 2018).

A indústria da moda, assim como outras indústrias produtoras de bens de consumo, é responsável por gerar impactos negativos no meio ambiente. Isso se deve, em grande parte à alta sazonalidade dos produtos, constantemente renovados de acordo as tendências relativas às estações do ano, o que aumenta o consumo deste tipo de produto, bem como o descarte de resíduos gerados pela indústria de confecções.

Para Sampaio et al. (2018), os impactos ambientais decorrentes do consumo excessivo apresentam um desafio contemporâneo, assim como as políticas de desenvolvimento e a própria lógica da obsolescência programada que rege os fluxos nas cadeias produtivas e nos processos de negócio.

Logo, se faz necessário um novo paradigma para este século, pautado principalmente pelo desenvolvimento sustentável. Este paradigma apresenta uma perspectiva voltada para uma economia que deixa de ser um fim para se transformar em uma nova forma de alcançar o bemestar das pessoas e do meio ambiente.

Tendo em vista o cenário apresentado, a pesquisa pretende responder ao seguinte questionamento: Como sintetizar estratégias voltadas ao design de moda para a sustentabilidade junto ao processo de desenvolvimento de produtos?

Além de buscar respostas ao questionamento apresentado, a presente pesquisa busca elucidar conceitos acerca dos termos desenvolvimento sustentável e design para a sustentabilidade, explanando práticas mais eficientes voltadas ao design de moda que possam ser integradas ao processo de desenvolvimento de produtos. 
Desse modo, tal estudo abrange a explanação das estratégias voltadas ao design para a sustentabilidade definidas por Vezzoli (2018), Salcedo (2014), Fletcher e Grose (2011) e Santos (2009), com a intenção de oportunizar reflexões acerca de como estas estratégias podem ser integradas a fim de direcionar a prática profissional do designer de moda ao desenvolver produtos de moda mais sustentáveis. Para tal, buscou-se como metodologia a revisão bibliográfica integrativa (RBI) associada à representação gráfica de síntese (RGS) com a montagem de uma mandala circular, a fim de representar a síntese de estratégias de design para a prática do designer de moda.

Visando a compreensão do assunto estudado, este artigo está dividido em quatro seções. Inicialmente apresenta a introdução, na segunda seção é realizada a revisão de literatura. Esta se baseia nos conceitos de desenvolvimento sustentável e design para a sustentabilidade bem como nas estratégias para a concepção de produtos de moda a partir dos estudos sobre Sistema Produto + Serviço de Vezzoli (2018), Moda ética para um futuro sustentável de Salcedo (2014), Design para a mudança, das autoras Fletcher e Grose (2011) e Design para a sustentabilidade de Santos (2009). $\mathrm{Na}$ terceira seção são descritos o método de revisão bibliográfica integrativa (RBI) associado à representação gráfica de síntese (RGS). Na quarta seção é apresentado o processo de construção da mandala circular e, para finalizar, são expostas as considerações finais da pesquisa.

\section{REVISÃO BIBLIOGRÁFICA}

\subsection{DESENVOLVIMENTO SUSTENTÁVEL}

Considerando o atual cenário de degradação ambiental, aliado a atitudes de consumo compulsivo geradas pelo sistema capitalista, vê-se como fundamental o conhecimento do designer de moda a respeito dos conceitos de produtos e serviços sustentáveis durante o processo de concepção de novos produtos.

Constata-se a partir de estudos de Papanek (2009), Manzini e Vezzoli (2011), Fletcher e Grose (2011), Salcedo (2014) e Vezzoli (2018), a preocupação com relação ao futuro da 
sobrevivência da humanidade dado o atual cenário de insustentabilidade ambiental. Desse modo, ambos os autores argumentam a favor de uma visão de sistemas mais integrada, onde o bem-estar econômico depende do bem-estar social, que por sua vez, depende do bem estar do meio ambiente (SALCEDO, 2014). Para tanto, tais estudiosos destacam a importância da compreensão do termo sustentabilidade, hoje tão em voga em todas as áreas.

Como ponto de partida, são destacadas a Conferência Científica da Organização das Nações Unidas (ONU-1949) sobre a Conservação e Utilização de Recursos e a Conferência sobre a Biosfera, realizada em Paris em 1968 nas quais surgiram estudos e debates a nível internacional sobre o meio ambiente. Além disso, pode ser citada a Conferência Mundial sobre o Meio Ambiente Humano (I CNUMAD) também conhecida como Comissão Brundtland, realizada pelas Nações Unidas em Estocolmo em 1972. Nela foram abordadas discussões relativas ao meio ambiente, ao desenvolvimento e ao modelo econômico seguido pelos países industrializados, dando origem à Declaração sobre o Meio Ambiente Humano, a qual determinava ações para a conservação ambiental tendo em vista a continuidade das espécies no planeta (VEZZOLI, 2018).

A partir de 1980, iniciaram-se debates mais intensos e significativos acerca das questões ambientais. Segundo Salcedo (2014), em 1987 a Organização das Nações Unidas (ONU) elaborou um relatório de caráter socioeconômico, no qual foi utilizado pela primeira vez o termo "desenvolvimento sustentável". Este foi definido como: "O desenvolvimento que satisfaz as necessidades do presente sem comprometer a satisfação das necessidades das gerações futuras" (SALCEDO, 2014, p.14).

Seguindo a mesma linha, outra definição foi proposta pelo The Natural Step (TNS, 1992), ao afirmar que "sustentabilidade é a habilidade de nossa sociedade humana em perpetuar-se dentro dos ciclos da natureza" (SALCEDO, 2014, p. 14).

Para Vezzoli (2018), foi somente a partir dos anos 1990 que as questões ambientais alcançaram sua fase de maturidade, com a publicação de "Cuidando da Terra: uma Estratégia para a Vida Sustentável" produzida pela International Union for Conservation of Nature (IUCN), Programa das Nações Unidas para o Meio Ambiente (UNEP) e o World Wide Fund for Nature (WWF), apresentando a seguinte definição para o desenvolvimento sustentável: "melhorar a qualidade de vida da humanidade dentro dos limites da capacidade de proteger os ecossistemas", tal definição possibilitou um maior entendimento a respeito da necessidade de melhoria das 
condições de vida do homem, bem como da manutenção, proteção e regeneração do ecossistema (VEZZOLI, 2018).

Tais iniciativas, segundo o autor, favoreceram de forma inegável a integração consistente do conceito de desenvolvimento sustentável ao propor acordos internacionais com base na promoção do respeito a equidade social e a integridade do meio ambiente global, levando em consideração as interdependências existentes no planeta.

Em linhas gerais, o tema desenvolvimento sustentável, alcançou grande evolução teórica, mas segundo Vezzoli (2018), são necessárias reflexões com relação aos avanços na prática. Por esta razão, cabe uma explanação sobre as dimensões da sustentabilidade, no sentido de direcionar as estratégias de operacionalização das ações na área da sustentabilidade.

Dentro da área de conhecimento dos estudos voltados à sustentabilidade, destaca-se a contribuição de Ignacy Sachs (2002) na abordagem de três dimensões interconectadas: a dimensão ambiental, a dimensão social e a dimensão econômica.

A dimensão ambiental trata das ações para não exceder os limites de resiliência da biosferageosfera. A dimensão social aborda a equidade e coesão social, e a dimensão econômica diz respeito a ações voltadas à ampliação do valor econômico, dentro de um continuum que vai da visão econômica ortodoxa até a visão da economia verde (VEZZOLI, 2018). A Figura 1 apresenta a integração das três dimensões da sustentabilidade.

Figura 1 - Dimensões da Sustentabilidade

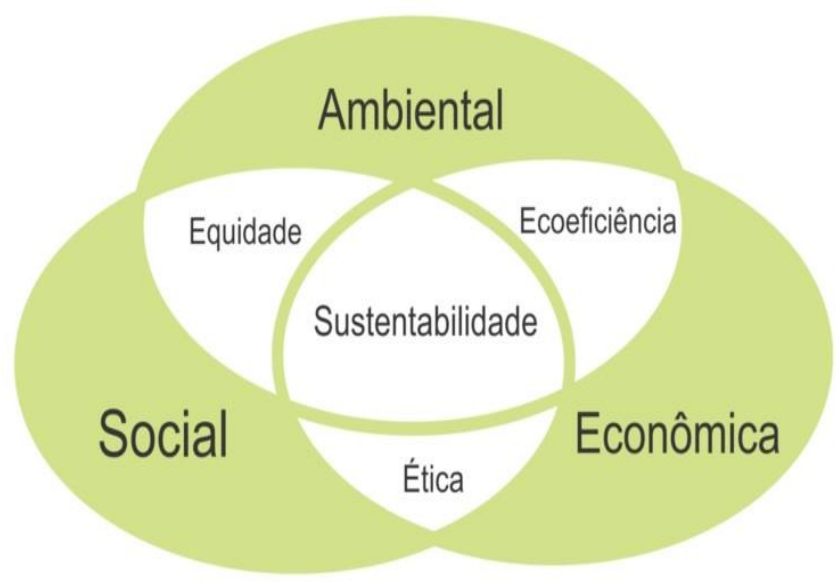

Fonte: Adaptado de Vezzoli (2018) 
Vezzoli (2018) aponta que entre as três dimensões do desenvolvimento sustentável, a dimensão ambiental é a que tem recebido maior ênfase no ambiente da pesquisa em design para a sustentabilidade. Para tanto, existem métodos e ferramentas disponíveis para instrumentalizar a prática do profissional bem como a formação de futuros profissionais designers (VEZZOLI, 2018).

Para Salcedo 2014), tais dimensões são os alicerces fundamentais para a mudança social ao considerar a incorporação de princípios ambientais e ferramentas como a análise do ciclo de vida, a fim de propor novas soluções em produtos e serviços, tendo em vista novos cenários, alicerçados nas referidas dimensões.

Portanto, se faz necessária uma transformação iminente com relação a tais comportamentos no que tange a produção e consumo baseados no design para a sustentabilidade, conforme exposto a seguir.

\subsection{DESIGN PARA A SUSTENTABILIDADE}

O design para a sustentabilidade é um campo de pesquisa onde se buscam novas alternativas de produtos e processos que minimizem os impactos ambientais decorrentes do sistema de produção e consumo vigente. A literatura clássica dessa área, se iniciou com ações e posicionamento de William Morris e John Ruskin passando por Victor Papaneck, Tomás Maldonado, Gui Bonsiepe, chegando a Victor Margolin e Klaus Krippendorff (MANZINI e VEZZOLI, 2011; VEZZOLI, 2018).

Manzini e Vezzoli (2011) apresentam quatro abordagens possíveis em design para a sustentabilidade com foco na redução de impactos ambientais causados pelos produtos, ou considerando o sistema como um todo.

Já para Santos (2009), a sustentabilidade requer um processo de reposicionamento dos modos de vida da sociedade, o que implica em novos processos de aprendizagem coletiva. Por ser considerado lento e complexo, o progresso em direção à sustentabilidade segue um caminho evolucionário. Este caminho é representado por diferentes níveis, onde a ascensão para um nível superior requer o entendimento e o exercício do nível anterior. A Figura 2 apresenta o processo rumo ao consumo sustentável. 
Figura - 2 Processo evolucionário em direção ao consumo sustentável

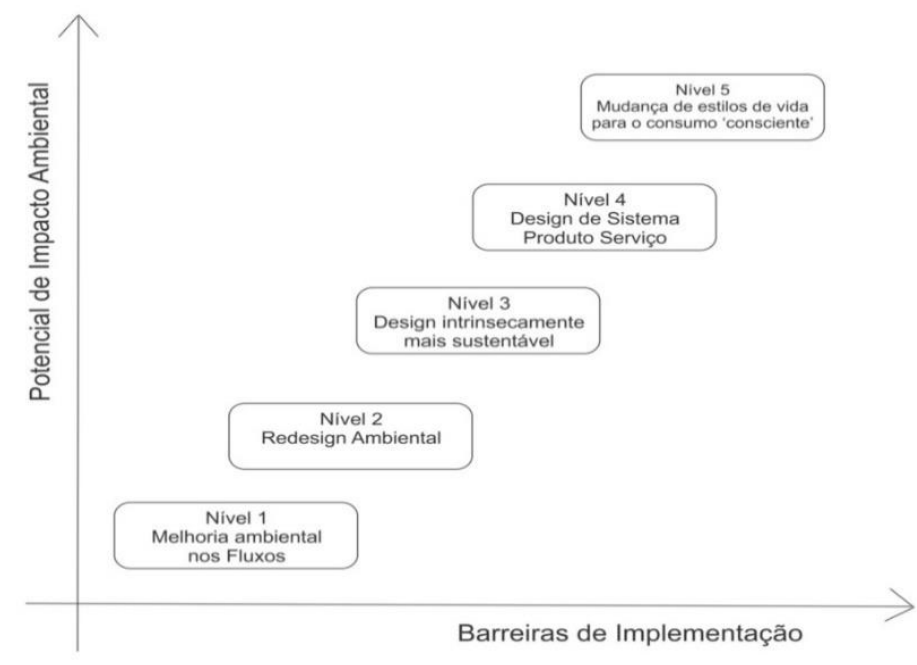

Fonte: Santos (2009)

Assim, Santos (2009) afirma que no nível 1 os esforços são orientados para a melhoria do desempenho ambiental dos fluxos de processos (materiais e/ou informação) e de operações (pessoas e/ou máquinas), com ênfase na seleção adequada de materiais e energia.

No nível 2, a abordagem tem seu foco numa readequação ambiental de um produto existente, assim como afirma Vezzoli (2018), podendo atuar a partir do redesign ou do design de novos produtos intrinsecamente sustentáveis.

Quanto a abordagem no nível 3, esta procura estabelecer soluções, ainda na fase de projeto, para melhorar o desempenho do produto em todas as etapas do ciclo de vida, partindo do próprio conceito do produto.

Já o nível 4, busca desmaterializar todo ou parte do consumo mediante a satisfação do usuário via serviços associados ao produto numa abordagem sistêmica baseada no Sistema Produto + Serviço (PSS), assim, pode-se repensar todo o sistema de produção e consumo à volta deste, ou seja, todo o ciclo de vida, que envolve também uma série de operações complementares, serviços e outros elementos.

O nível 5, requer maior complexidade quando propõe ações orientadas à esfera sociocultural, promovendo novos critérios qualitativos associados à percepção de satisfação e felicidade pelo ser humano de forma a resultar em consumo suficiente (SANTOS, 2009). Neste caso, 
é possível propor serviços que busquem desmaterializar o consumo, bem como criar novas propostas de cenários de estilos de vida mais sustentáveis.

Compartilhando deste mesmo entendimento, Manzini e Vezzoli (2011) apontam que é somente a partir desta possibilidade que pode haver soluções realmente coerentes com a perspectiva de sustentabilidade e, portanto, um design sustentável.

Os novos produtos-serviços podem tornar-se intrinsecamente sustentáveis caso consigam superar a inércia cultural/comportamental dos consumidores, mas devem ser considerados pelas empresas que os fornecem de forma estratégica em seus negócios. Nesse contexto, abordagens mais recentes levam em conta não somente a forma de produção, mas consideram todo o ciclo de vida dos materiais nas fases de distribuição, uso e eliminação (MANZINI; VEZZOLI, 2011).

No que diz respeito à indústria da moda, Salcedo (2014) afirma que esta engloba não apenas a concepção de peças com materiais mais sustentáveis. Para a autora, o grande desafio é conseguir repensar e redefinir a forma de desenhar, produzir, distribuir e utilizar as peças, o que deve ter início já na fase de concepção da mesma. Esta atividade se dá a partir do momento em que o designer incentiva a utilização de processos de produção mais sustentáveis e a mudança de comportamento por parte do consumidor no que se refere ao uso e ao consumo das peças, assim, deixa-se de falar em design sustentável e passa-se a falar em design para a sustentabilidade.

Além disso, Salcedo (2014), aborda a estratégia de sustentabilidade como uma oportunidade de inovação.

Neste cenário, Fletcher e Grose (2011) argumentam que a inovação com foco na sustentabilidade de produtos de moda, apresenta uma visão mais abrangente do ciclo de produção e consumo, na qual a mudança deve concentrar-se em nos aspectos sociais e ambientais presentes ao longo do ciclo de vida do produto, ou seja, desde a fibra têxtil, passando pelos processos produtivos, pelo consumidor, até o local de descarte e uma eventual reutilização.

Tal visão reflete um modo de pensar que concebe cada fase do sistema vinculada a todas as outras, reconhecendo a necessidade de mudança e melhorias em todo o ciclo da moda.

Para Vezzoli (2018), um dos grandes desafios a serem superados ligados ao paradigma do desenvolvimento sustentável, onde a produção de bem estar substitui a busca pela produção de produtos, configura-se em uma mudança radical em relação ao pensamento ortodoxo do crescimento, e para tanto, destaca que o design tem contribuído para esta perspectiva de evolução 
econômica da sociedade. Conforme Vezzoli (2018) o conceito de design da forma como vem sendo trabalhado está ligado, diretamente, à cultura do consumo, tendo como objetivo dar forma a produtos para a produção em massa.

Em contrapartida, o designer orientado para o desenvolvimento econômico e humano, busca em paralelo ao desenvolvimento econômico, mudanças gradativas ao longo do tempo, a fim de beneficiar toda a população por meio da promoção de melhorias no padrão de vida material, nas condições de saúde e consequentemente na longevidade, além disso pretende ampliar o exercício da cidadania, as oportunidades de aperfeiçoamento pessoal, e a qualidade da preservação e conservação do meio ambiente (VEZZOLI, 2018).

Percebe-se que tais soluções bem intencionadas na dimensão ambiental e social frequentemente esbarram em obstáculos relacionados justamente à dimensão econômica. Além disso, mesmo que se tenha alcançado uma solução economicamente viável, reforça-se a importância de se entender as divergências entre a racionalidade econômica ortodoxa (baseada na procura da eficiência econômica) e a racionalidade ecológica (baseada na contenção do consumo dos recursos ambientais e na justiça social), onde quem persegue a primeira tem dificuldade em atingir a segunda (MANZINI e VEZZOLI, 2011).

Diante do exposto, tendo em vista os modelos ortodoxos de comercialização de produtos, Vezzoli (2018) destaca que o design para a sustentabilidade viabilizado pelo PSS, busca a conversão de oportunidades de mercado em soluções efetivas que possibilitem novos cenários de vida mais sustentáveis, ampliando as possibilidades de inovação para além do produto.

Assim, o debate em torno da sustentabilidade através do Sistema Produto + Serviço (PSS), está ligado ao esforço em tornar o sistema competitivo ao mesmo tempo em que satisfaça as necessidades dos clientes, além de apresentar menor impacto do que os modelos tradicionais de negócio, dificultando desta maneira, as pesquisas na área (VEZZOLI, 2018).

Vezzoli (2018), salienta ainda, que a transição de um sistema econômico baseado na produção e consumo para um modelo baseado na desmaterialização dos produtos é um dos vários caminhos possíveis na busca de padrões de vida mais sustentáveis.

Para tanto, considera-se fundamental dentro de uma perspectiva de desenvolvimento sustentável, mapear as interações, relações e estratégias voltadas à concepção de produtos em 
todo o sistema da moda, levando em consideração o ciclo de vida e o papel do designer diante deste cenário, conforme será apresentado na sequência.

\subsection{ESTRATÉGIAS NA CONCEPÇÃO DE PRODUTOS DE MODA SUSTENTÁVEIS}

Esta seção apresenta as pesquisas no campo da moda mais sustentável, trazendo como referências os autores: Manzini e Vezzoli (2011), Fletcher e Grose (2011), Salcedo (2014) e Vezzoli (2018), que tratam da concepção de produtos sustentáveis a partir do ciclo de vida destes numa visão aberta e sistêmica, com o objetivo de oferecer condições e oportunidades de reflexão e estratégias para os profissionais da área na concepção de produtos de moda sustentáveis.

\subsubsection{SISTEMA PRODUTO + SERVIÇO SUSTENTÁVEL- VEZZOLI (2018)}

Na obra de Vezzoli (2018) que trata do Sistema Produto + Serviço Sustentável (PSS), é imperativa a necessidade de uma descontinuidade sistêmica nos padrões de produção e consumo, visto que o autor aponta os modelos ortodoxos de comercialização dos produtos como uma das maiores barreiras para a implantação dos princípios do Projeto do ciclo de vida dos produtos.

Dentro deste cenário, Vezzoli (2018, p.63) define Sistema Produto + Serviço (PSS), como sendo um sistema que "resulta de uma estratégia de inovação que muda o centro do negócio do projeto (design) e a venda de produtos (física) para sistemas que oferecem produtos e serviços capazes de satisfazer a demanda".

Assim, para Vezzoli (2018), o PSS tem como característica a mudança de enfoque de produtos físicos para um sistema ecoeficiente integrado que visa oferecer soluções inovadoras entre os atores.

Desta maneira, o potencial para a criação de valores fica dissociado do consumo de recursos, mas para que isso se concretize, conforme Vezzoli (2018), a reconfiguração do sistema é fundamental, sendo o ponto de partida o projeto de produtos orientados ao ciclo de vida, onde ocorra a ampliação das possibilidades de inovação para além do produto. Sob este aspecto, a ênfase recai na satisfação final do usuário, respeitando os limites de resiliência ambiental e as demandas sociais do entorno. Essa oferta combinada de produtos e serviços que possam levar a realização de uma unidade de satisfação é chamada de Sistema Produto-Serviço (PSS) (VEZZOLI, 2018). 
Assim, faz-se importante considerar a sustentabilidade como valor, quando Vezzoli (2018) destaca a possibilidade de distinção, onde de um lado a sustentabilidade é vista na perspectiva do produto, e de outro na perspectiva do usuário, que nesse caso leva em conta a sua relação (comportamento) com o produto como parte importante para a sustentabilidade. Nesse sentido, passa de uma visão com enfoque nos meios de produção, para uma visão aberta e sistêmica, tendo em vista os envolvidos, o processo produtivo, e a fase de consumo do produto.

Para melhor entendimento acerca do tema, Vezzoli (2018), destaca ainda as três principais abordagens de negócios para inovações de sistemas que têm sido estudadas e apontadas como favoráveis para a ecoeficiência. São elas: PSS orientado ao produto: serviços que agregam valor ao ciclo de vida do produto; PSS orientado ao uso: serviços que fornecem plataformas facilitadoras aos clientes; PSS orientado ao resultado: serviços que fornecem resultados finais para os consumidores.

Segundo o autor:

(...) os três tipos de abordagens de inovações de Sistema (PSS) ecoeficientes agregam valor ao ciclo de vida do produto (PSS orientado ao "produto"), ao oferecer plataformas facilitadoras aos clientes (PSS orientado ao "uso") e oferecer resultados finais (PSS orientado ao "uso") - apresentam soluções favoráveis tanto ambientalmente quanto economicamente (...) mostram que a interação inovadora entre o cliente e o fornecedor, bem como os outros atores (stakeholders) do sistema de produção podem alcançar soluções mutuamente benéficas, onde o mesmo interesse econômico leva a inovações que reduzem o impacto ambiental (VEZZOLI, p. 81, 2018).

Para Vezzoli (2018), são várias as vantagens em cada uma das dimensões ligadas a inovação em PSS, conforme apresenta a Figura 3:

Figura 3 - Tipos de inovação a partir do PSS

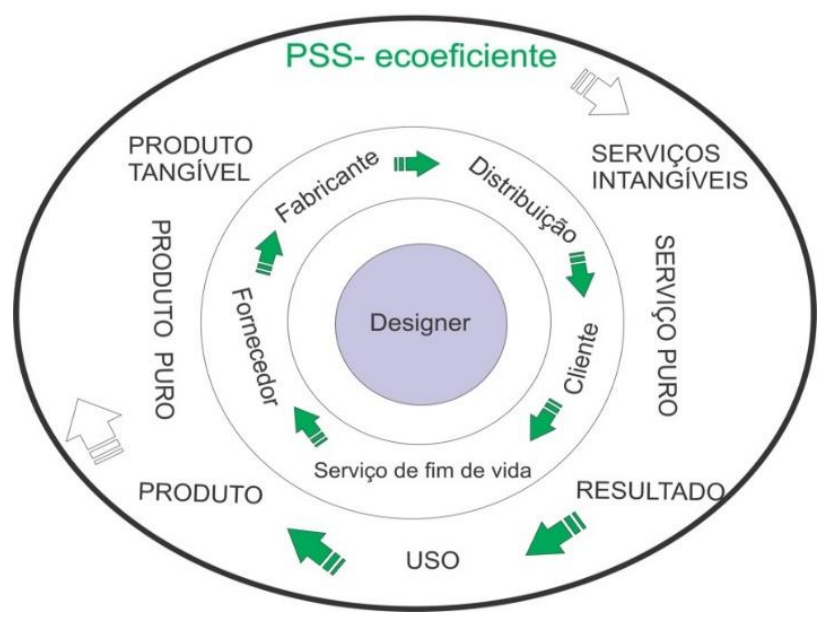

Fonte: Adaptado de Vezzoli (2018) 
Aqui faz-se importante destacar, que tal sistema possibilita a integração de soluções de bens e serviços de forma a garantir uma maximização dos recursos físicos, trazendo benefícios também para os usuários ao oferecer serviços de ampliação da vida útil do produto. Neste sentido, o designer deve estar sempre pesquisando novas tecnologias e novos processos de inovação com o objetivo de gerar soluções para os problemas da sociedade atual.

Dessa forma, o PSS pode ser considerado uma alternativa para as empresas que buscam inovação em seus negócios. A adoção do PSS por uma empresa promove mudanças em seu modelo de negócio e em seus processos de negócio, principalmente nos casos de tipos de PSS orientados ao uso e ao resultado.

\subsubsection{MODA ÉTICA PARA UM FUTURO SUSTENTÁVEL- SALCEDO (2014)}

Ao compreender o design para a sustentabilidade, constata-se com base nos estudos de Salcedo (2014), que o profissional envolvido no processo precisa entender que a sustentabilidade não é algo a ser agregado e sim parte do processo de design. Isso amplia as oportunidades para a geração de novas alternativas já na fase de concepção ou de pesquisa, ao invés de apenas pensar em ações para reduzir o impacto ambiental durante as fases de seleção de materiais ou produção da peça. Corroborando com tal afirmativa, pode ser citado Lawson (apud SALCEDO, 2014), cujo trabalho sugere que o estilista desenvolva linhas paralelas de pensamento que permitam trabalhar simultaneamente diferentes aspectos do design. A Figura 4, elaborada com base no método de linhas paralelas de pensamento de Lawson presente na obra de Salcedo (2014), apresenta as estratégias de design para a sustentabilidade.

Figura 4 - Estratégias de Design para a Sustentabilidade segundo Salcedo (2014)

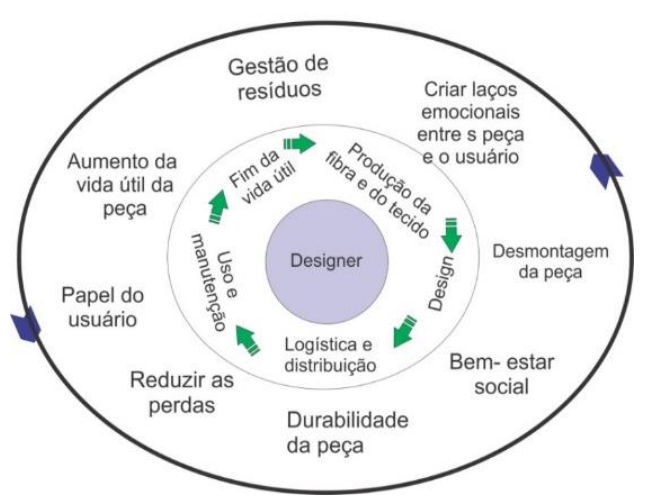

Fonte: Adaptado de Salcedo (2014) 
Este enfoque relacionado ao ciclos de design e produção, segundo Salcedo (2014), reflete estratégias de design para a sustentabilidade ao oferecer maiores possibilidades de agregar pensamentos aplicáveis ao longo do ciclo de vida do produto com vistas a uma mudança de paradigma, onde o design para a sustentabilidade rompe com o sistema vigente da indústria da moda. Para tanto, o ponto relevante para a mudança estaria inicialmente na compreensão do processo de design a partir da abordagem do ciclo de vida útil do produto de moda, num sistema mais integrado, e onde as relações fossem mais próximas entre todos os envolvidos no processo de forma colaborativa e responsável com a intenção de compreender todo o ciclo.

\subsubsection{DESIGN PARA A MUDANÇA - FLETCHER E GROSE (2011)}

Para Fletcher e Grose (2011), as transformações no campo da sustentabilidade estão ligadas a grandes transformações nos novos modos de pensar, produzir e fazer negócio. Desse modo, buscam estratégias ligadas ao ciclo de vida, levando em consideração num primeiro momento as transformações dos produtos de moda (materiais, processos, distribuição, cuidados do consumidor, descarte), num segundo momento as transformações no sistema de moda (adaptabilidade, vida útil otimizada, usos de baixo impacto, serviços e compartilhamento, local, biomimética, velocidade, necessidades e engajamento), e por fim, a transformação na prática do design de moda (designer como educador-comunicador, facilitador, ativista e empreendedor).

Dentro deste contexto, as autoras afirmam que: "a mentalidade sustentável baseia-se em reciprocidade e complexidade, e em uma profunda compreensão dos padrões, das redes, dos equilíbrios e dos ciclos em jogo no sistema da moda" (FLETCHER E GROSE, 2011, p. 11).

Portanto, a busca por melhorias na produção de moda mais sustentável deve buscar maior reflexão e compreensão de todos os atores ao utilizar o conceito de logística reversa ${ }^{1}$, representado pela Figura 5:

\footnotetext{
${ }^{1}$ Processo de planejamento, implementação e controle do fluxo eficiente e de baixo custo de matérias primas, estoque em processo, produto acabado e informações relacionadas, desde o ponto de consumo até o ponto de origem, com o propósito de recuperação de valor ou descarte apropriado para coleta e tratamento de lixo (DAHER, SILVA e FONSECA, 2006).
} 
Figura 5 - Logística Reversa por Fletcher e Grose (2011)

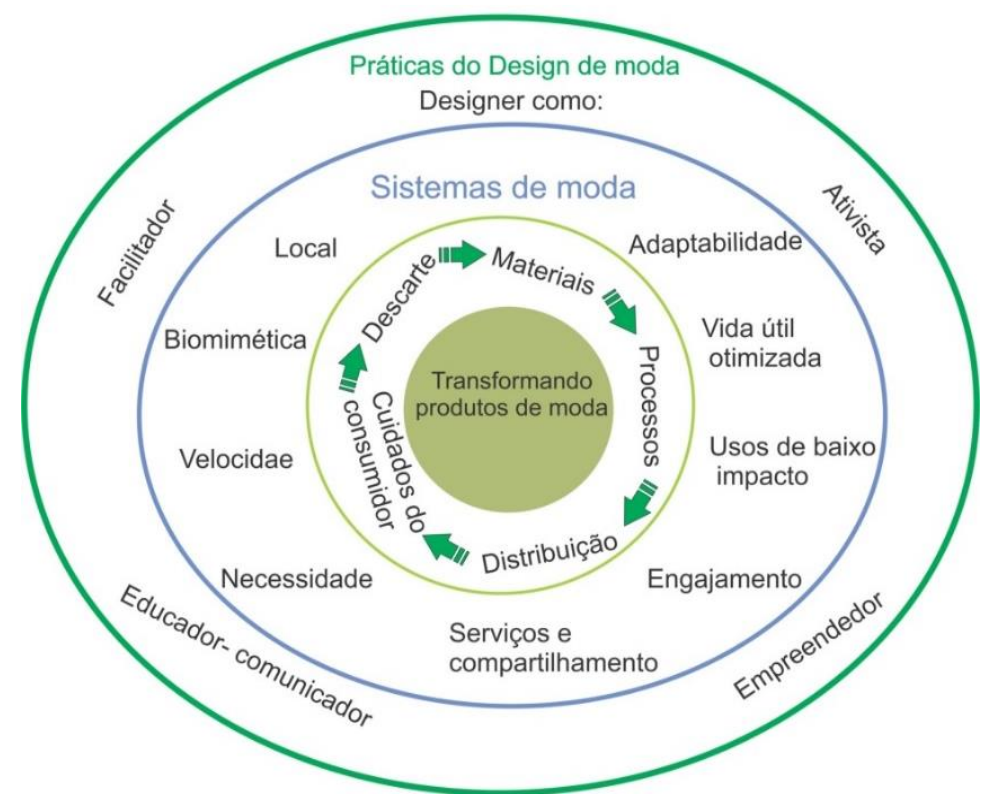

Fonte: Adaptado de Fletcher e Grose (2011)

Tais transformações apontadas pelas autoras refletem um sistema complexo e amplo, onde as estratégias para a mudança incluem a intervenção em produtos e sistemas nas diferentes práticas, desde as ligadas à concepção de produtos, os sistemas de moda, e finalmente nas práticas do design para a sustentabilidade. É possível destacar na figura 5, a importância de novos modelos de negócios e produção a partir de estratégias inovadoras de design, onde exista maior conexão entre a sociedade e a natureza, desacelerando a produção e o consumo de massa através de novos modelos de interação econômica, social e ambiental.

\section{METODOLOGIA}

A construção deste estudo foi orientada pelo método de Revisão Bibliográfica Integrativa (RBI) associado à Representação Gráfica de Síntese (RGS).

Para Souza, Silva e Carvalho (2010), a Revisão Bibliográfica Integrativa é um método que proporciona a síntese de conhecimento e a incorporação da aplicabilidade de resultados de estudos significativos na prática. É uma das mais amplas abordagens metodológicas referente às revisões, permitindo a inclusão de estudos experimentais e não-experimentais para uma compreensão completa do fenômeno analisado. Combina também dados da literatura teórica e empírica, além de incorporar um vasto leque de propósitos: definição de conceitos, revisão de teorias e evidências, e análise de problemas metodológicos de um tópico particular. 
Representações Gráficas de Síntese - RGSs, segundo Bueno e Padovani (2015, p. 375), são entendidas como "artefatos cognitivos, um dispositivo artificial projetado para manter, apresentar ou operar informação, e que cumpre uma função comunicacional". No mesmo sentido, Bueno e Padovani (2015) argumentam que as RGSs são artefatos visíveis bidimensionais estáticos criados com o objetivo de complementar a informação escrita. Elas fazem uso direto da linguagem visual, que são compostas basicamente por imagens, palavras e formas.

Neste sentido, o processo de elaboração do estudo, obedeceu às seguintes etapas: Definição do Problema de Pesquisa, Seleção da Literatura, Leitura e Análise dos Materiais, Construção da RGS.

Logo, o problema investigado abordou um processo de sintetização de estratégias voltadas ao design de moda para a sustentabilidade junto ao processo de desenvolvimento de produtos.

As estratégias resultaram de pesquisas presentes na literatura relacionada ao design para a sustentabilidade. A seleção da literatura, leitura e análise dos materiais possibilitou a reflexão necessária para a construção dos argumentos apresentados. A escolha pelos autores utilizados, deu-se por considerá-los referências internacionais nos assuntos ligados ao design de produto, moda e sustentabilidade, oferecendo ampla discussão e análises atualizadas acerca dos termos e reflexões no campo da pesquisa, numa linha de pensamento global e sistêmica.

Após a análise da literatura selecionada, procedeu-se à construção de uma Representação Gráfica de Síntese (RGS) na qual foram sintetizadas as estratégias voltadas ao Design para a Sustentabilidade elencadas por Vezzoli (2018), Salcedo (2014), Fletcher e Grose (2011) e Santos (2009). O design da RGS bem como suas implicações teóricas encontram-se na próxima seção.

\subsection{CONSTRUÇÃO DA RGS}

As estratégias voltadas ao design para a sustentabilidade estudadas por Vezzoli (2018), Salcedo (2014) e Fletcher e Grose (2011) e Santos (2009) serviram como base para a estruturação de uma Representação Gráfica de Síntese (RGS).

De acordo com Paixão et al. (2017), as RGSs podem ser: lógicas, metafóricas ou configuracionais. Para este estudo, foram utilizados os tipos metafóricos, onde os indivíduos 
utilizam imagens familiares como pontes, funis, montanhas, árvores ou meteorologia para expressar ideias ou insights.

Assim, a fim de sintetizar as estratégias voltadas ao design de moda para a sustentabilidade junto ao processo de desenvolvimento de produtos, optou-se pela construção de uma Representação Gráfica de Síntese no formato de uma mandala (figura 7)

A mandala foi escolhida por representar a aliança entre as peculiaridades da moda e o ecossistema em que ela está inserida, sendo utilizada como elemento de ligação harmônica e integração dos sistemas produtivos. Tal representação busca oferecer ao designer de moda possibilidades de correlação entre os níveis de maturidade e dimensões da sustentabilidade oportunizando reflexões acerca das estratégias do design para a concepção de produtos de moda mais sustentáveis, a partir dos estudos de Vezzoli (2018), Salcedo (2014) Fletcher e Grose (2011), Santos (2009), na medida que ambos dispõem de estudos baseados em abordagens sistêmicas abertas.

Para melhor compreensão, a representação da mandala circular foi disposta inicialmente em níveis de complexidade, conforme pode ser observado na figura 6 (níveis 1 e 2).

Não obstante, o designer é visto aqui, como o ator central do sistema de moda, e, a partir de sua atuação, possui como propósito integrar e dinamizar as relações entre as dimensões na concepção dos produtos de moda, com ampla visão e conhecimento dos sistemas econômicos, sociais e ambientais de maneira sistêmica, projetando com coerência e comprometendo-se com a ética por meio de produtos de moda mais sustentáveis.

Neste sentido, no eixo central está localizado o designer como gerador de um novo valor social. Este se relaciona aos elos entrelaçados que formam tríades num primeiro nível. As tríades alicerçam os princípios e dimensões da sustentabilidade, no sentido de direcionar as estratégias de operacionalização das ações. Em seguida, há uma progressão gradativa em direção a outros elos interligados, onde os níveis de maturidade evoluem em direção à sustentabilidade num caminho evolucionário e sistêmico. Isso possibilita a compreensão de todo o ciclo de vida útil do produto de moda em direção a novos estilos de vida, elucidando a efetiva mudança de paradigma respeitando os níveis de maturidade da sustentabilidade propostos por Santos (2009), conforme podem ser observados na figura 6, representando separadamente os níveis 1 e 2: 
Figura 6 - Níveis representativos da mandala circular

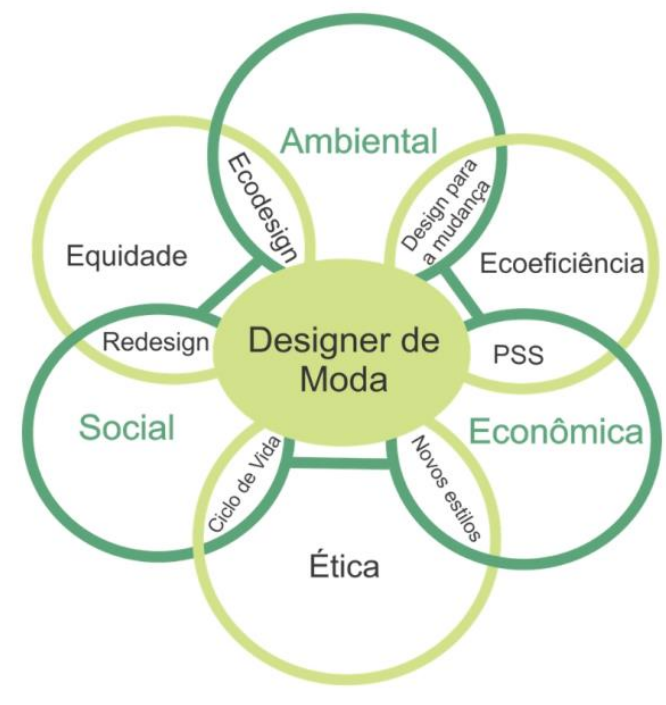

Nível 1:

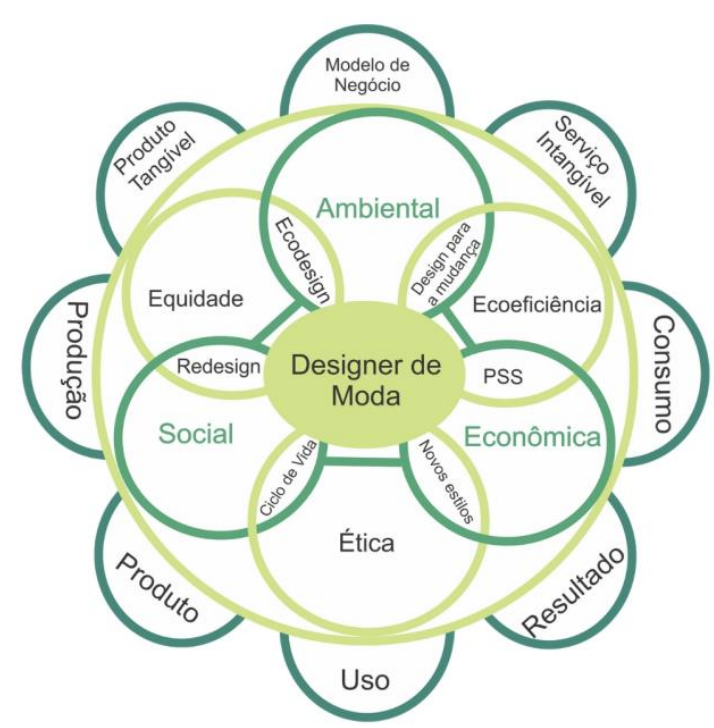

Nível 2:

Fonte: As autoras, 2018

No segundo nível, estão dispostos os sistemas que possibilitam a integração das soluções de bens e serviços (VEZZOLI, 2018). Estes garantem melhores resultados quanto a maximização e aproveitamento de recursos físicos com benefícios aos usuários na oferta de serviços de ampliação da vida útil do produto de moda.

Tais serviços se relacionam com o terceiro e último nível representado pelas estratégias extraídas de Salcedo (2014) e Fletcher e Grose (2011), sendo estas ligadas às transformações do sistema de moda que, por consequência, promovem mudanças na prática do designer de moda.

As estratégias consistem em:

- Usos de baixo impacto: seleção de matérias primas sustentáveis e de baixo impacto ambiental.

- Necessidade: inovação na forma de ver e usar a roupa, oferecendo ao consumidor possibilidades criativas e atitudes colaborativas.

- Laços emocionais: conectar-se emocionalmente com a roupa ao identificar formas de produzi-las com maior compromisso entre o consumidor e a peça.

- Papel do usuário: conhecer as práticas de uso e manutenção das peças dentro dos parâmetros de um comportamento mais sustentável. 
- Compartilhamento: potencializar o uso de uma peça através de diferentes estratégias de marketing (aluguel, brechó, guarda-roupa compartilhado)

- Local: relação próxima entre a indústria, produtor e consumidor.

- Adaptabilidade: fazer o uso de estratégias de design, oferecendo peças multifuncionais, reversíveis, modificáveis, desmontáveis, além de matérias primas mais eficientes e sustentáveis que se adaptem as novas necessidades sociais.

- Gestão de resíduos: programada estrategicamente, viabilizando o descarte final da peça sem comprometer ou impactar agressivamente o meio ambiente.

Para finalizar, o conjunto completo está circundado pela borda circular em forma de seta, que representa o ciclo completo do sistema, conforme a figura 7.

Figura 7 - Estratégias de design para a concepção de produtos de moda mais sustentáveis

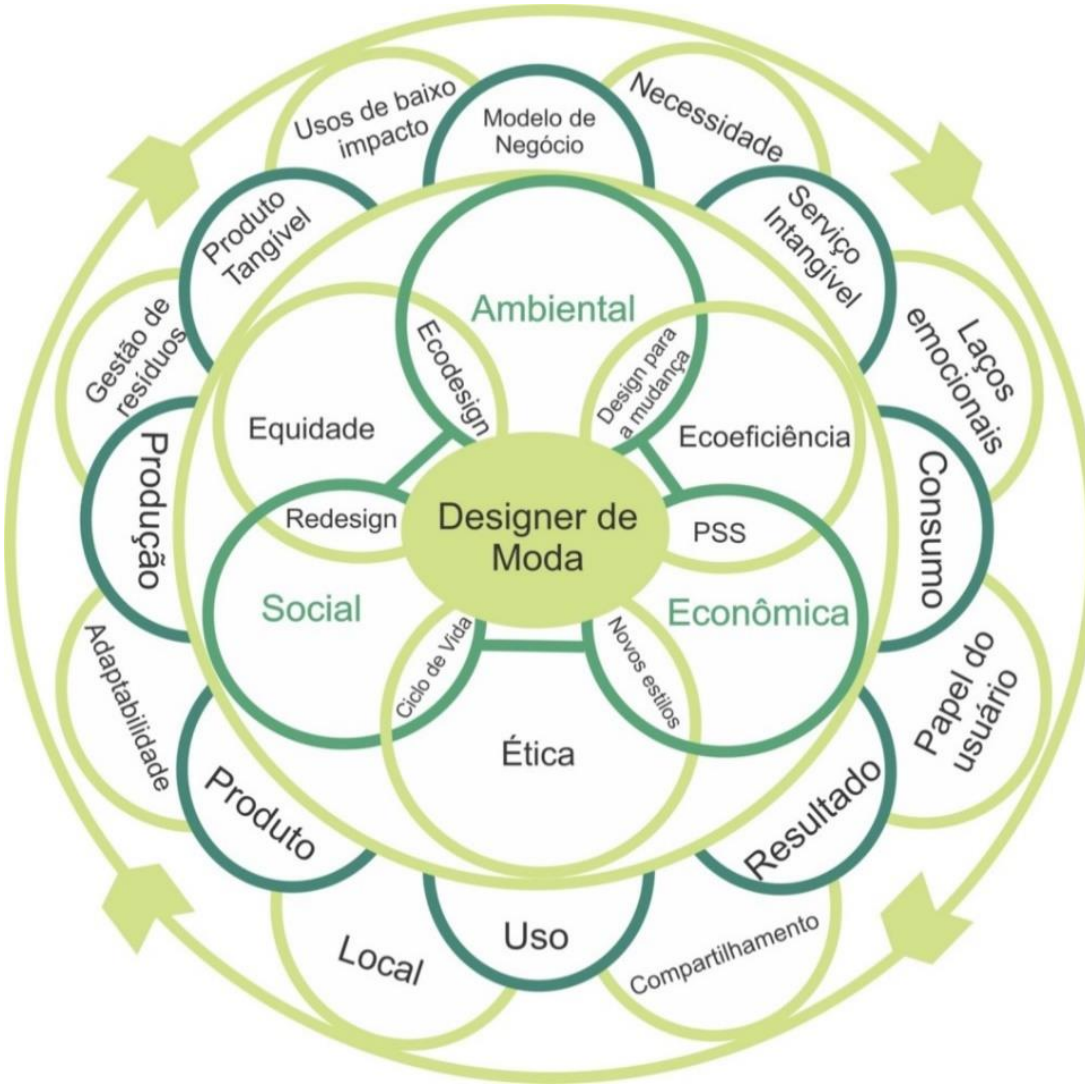

Fonte: As autoras, 2018

Tal representação buscou demonstrar a complexidade que envolve o sistema de moda como um todo, capaz de oferecer subsídios aos profissionais da área de design, na criação de novas estratégias ligadas a concepção de produtos de moda mais sustentáveis. 


\section{CONSIDERAÇÕES FINAIS}

Diante da complexidade dos conceitos e conhecimentos que envolvem o desenvolvimento sustentável e a produção da indústria da moda, na busca por mudança de paradigmas, existe a necessidade de grandes transformações, nos modelos de pensar, produzir e fazer negócio, tudo isso associado ao estabelecimento de estratégias ligadas ao ciclo de vida dos produtos e aos sistemas integrados.

Dentro deste cenário, a presente pesquisa se propôs a responder ao seguinte questionamento: Como sintetizar estratégias voltadas ao design de moda para a sustentabilidade junto ao processo de desenvolvimento de produtos?

Para tanto, inicialmente foram elucidados conceitos acerca do desenvolvimento sustentável, bem como design para a sustentabilidade.

Em relação a explanação do tema desenvolvimento sustentável foi realizado um levantamento cronológico acerca dos principais eventos e documentos oficiais que nortearam a criação e difusão do termo, enfatizando as dimensões ambiental, social e econômica. Desse modo, destaca-se que a dimensão ambiental é a mais enfatizada no ambiente da pesquisa em design para a sustentabilidade, contando com métodos e ferramentas para instrumentalizar a prática dos profissionais.

Em seguida, foi evidenciado o tema design para a sustentabilidade, campo de pesquisa que privilegia a minimização dos impactos ambientais decorrentes do sistema de produção e consumo vigente. A abordagem trouxe como aspectos relevantes a necessidade de processos de reposicionamento dos modos de vida da sociedade, bem como a possibilidade de se encontrar oportunidades de inovação, isso levando em conta uma visão mais abrangente do ciclo de produção e consumo.

Com o escopo teórico inicial definido, foram selecionadas fontes que tratassem de estratégias para concepção de produtos de moda sustentáveis, para então sintetizar essas estratégias em uma única configuração.

As estratégias para concepção de produtos de moda sustentáveis enfatizaram a concepção de produtos partindo de uma visão aberta e sistêmica. Assim, o sistema produto + serviço definido por Vezzoli (2018), trouxe como característica a mudança de enfoque de produtos físicos para um sistema ecoeficiente integrado, considerando a sustentabilidade como valor. A contribuição de 
Salcedo (2014), destacou a necessidade do entendimento da sustentabilidade como parte do processo de design. De modo semelhante, Fletcher e Grose (2011) reiteram que as transformações no campo da sustentabilidade estão ligadas a grandes transformações nos novos modos de pensar, produzir e fazer negócio, alicerçada na utilização do conceito de logística reversa.

Assim, seguindo a metodologia de construção de Representações gráficas de Síntese (RGS), as estratégias pesquisadas foram agrupadas no formato de uma mandala circular, entendida como uma representação gráfica metafórica que representa a aliança entre a moda e seu ecossistema em que ela está inserida.

A mandala foi disposta inicialmente em 2 níveis de complexidade, onde o designer foi inserido como ator central com o propósito de integrar e dinamizar as relações entre as dimensões na concepção dos produtos de moda, com ampla visão e conhecimento dos sistemas econômicos, sociais e ambientais a fim de projetar com coerência e comprometer-se com a ética por meio de produtos de moda mais sustentáveis.

Na representação gráfica também estão presentes tríades que alicerçam os princípios e dimensões da sustentabilidade num caminho evolucionário e sistêmico.

No segundo nível, estão dispostos os sistemas que possibilitam a integração das soluções de bens e serviços que se relacionam com o terceiro e último nível, representado pelas estratégias extraídas de Salcedo (2014) e Fletcher e Grose (2011).

A construção da mandala possibilitou a resposta ao questionamento inicial na medida em foram sintetizadas estratégias voltadas ao design de moda para a sustentabilidade oriundas do escopo teórico pesquisado.

Sob este ponto de vista, as estratégias apresentadas pelo estudo, implicam em grandes mudanças relacionadas ao modelo de vida capitalista em direção ao novo paradigma baseado na transparência, colaboração, lentidão, visão de longo prazo, tamanho ótimo, valor compartilhado, enfoque circular. Daí a importância do papel do designer de moda, pois para alcançar tal potencial de sustentabilidade, é preciso pensar em plataformas que transformem paradigmas, em vez de só pensarem em produtos e processos. Para que ocorram tais mudanças, é preciso atentar para critérios, métodos e ferramentas que orientam o designer para interações e relações entre atores (stakeholders) de sistemas ecoeficientes. 
Perante o exposto nesta pesquisa, foi possível concluir que o campo de estudo na área da sustentabilidade ligado à prática do designer de moda apresenta grandes desafios a serem superados por todos os atores do processo, inclusive os designers, por representarem um papel significativo que vai além de minimizar problemas, mas oferecer condições para um novo sistema de moda.

Por fim, cabe salientar a necessidade de ampliação de pesquisas no campo da formação e prática do designer de moda, ligados aos novos conceitos e estratégias para o desenvolvimento de produtos de moda mais sustentáveis.

\section{REFERÊNCIAS}

BUENO, J.; PADOVANI, S. Estudo do processo de aprendizagem colaborativa através das representações gráficas de síntese (RGSs). In: CONGRESSO INTERNACIONAL DE DESIGN DA INFORMAÇÃO, 7., 2015, Brasília. Anais eletrônicos [...]. Brasília : Blucher Design Proceedings, v. 2, n. 2, p. 374-385, set. 2015. DOI: 10.5151/designpro-CIDI2015-cidi_178. Disponível em: https://www.proceedings.blucher.com.br/article-list/cidi2015-255/list\#articles. Acesso em: 03 mar. 2020.

DAHER, C. E.; SILVA, E. P. de La S.; FONSECA, A. P. Logística Reversa: Oportunidade para Redução de Custos através do Gerenciamento da Cadeia Integrada de Valor. Brazilian Business Review , Vitória, v. 3, n. 1 , p. 58-73, jan./jun. 2006. Disponível em:

https://repositorio.unb.br/bitstream/10482/12550/1/ARTIGO_LogisticaReversaOportunidade.pdf. Acesso em: 21fev. 2020.

FLETCHER, K.; GROSE, L.(org.) Moda \& Sustentabilidade: design para mudança. São Paulo: SENAC, 2011.

MANZINI, E.; VEZZOLI, C. O desenvolvimento de produtos sustentáveis: os requisitos ambientais dos produtos industriais. São Paulo: Universidade de São Paulo, 2011.

PAIXÃO, W. et al. Criatividade e aprendizagem colaborativa através da produção de representações gráficas de síntese: uma experiência com alunos de artes visuais. In: CONGRESSO INTERNACIONAL DE AMBIENTES HIPERMÍDIA PARA APRENDIZAGEM, 16., 2017, Florianópolis. Anais eletrônicos [...]. Florianópolis : Blucher Design Proceedings, v. 3, n. 11, p. 483-495, jun. 2017. DOI:

10.5151/16ergodesign-0049. Disponível em: https://www.proceedings.blucher.com.br/articlelist/cinahpa2017-289/list\#articles. Acesso em: 18 out. 2018.

PAPANEK, V. Design for the real world: human ecology and social change. 2nd ed. Academy Chicago Publishers: Illinois, 2009. 
SACHS, I. Caminhos para o desenvolvimento sustentável. Rio de Janeiro: Garamond, 2002.

SALCEDO, E. Moda ética para um futuro sustentável. Barcelona: Editora Gustavo Gili, 2014.

SAMPAIO, C. P. de et al. Design para a sustentabilidade: dimensão ambiental. Curitiba: Insight, 2018.

SANTOS, A. Níveis de maturidade do design sustentável na dimensão ambiental. In: MORAES, D. de; KRUCKEN, L. (org.) Cadernos de estudos avançados em design. Barbacena : EdUEMG, 2009.

(Sustentabilidade;1). p.13-26. Disponível em: http://eduemg.uemg.br/images/livros-pdf/catalogo2009/2009_CADERNOS_DE_ESTUDOS_AVANCADOS_EM_DESIGN_SUSTENTABILIDADE_I_VOL_3.pdf . Acesso em: 31 mar. 2020

SOUZA, M. T; SILVA, M. D. da; CARVALHO, R. de. Revisão integrativa: o que é e como fazer. Einstein, São Paulo, v. 8, n. , p. 102-106, jan./mar. 2010. DOI: http://dx.doi.org/10.1590/s167945082010rw1134. Disponível em: https://www.scielo.br/pdf/eins/v8n1/pt_1679-4508-eins-8-10102.pdf. Acesso em: 17 abr. 2020.

VEZZOLI, C. et al. Sistema produto + serviço sustentável: fundamentos. Curitiba: Insight, 2018. Ebook. Disponível em: http://editorainsight.com.br/wp-content/uploads/2018/03/aSistemaProdutoServico-Sustentavel_web.pdf. Acesso em: 05 ago.2019. 